\title{
Labor Markets and Monetary Policy: A New-Keynesian Model with Unemployment*
}

\author{
Olivier Blanchard ${ }^{\dagger} \quad$ Jordi Gali ${ }^{\ddagger}$
}

March 6, 2008 (first draft: March 2006)

\begin{abstract}
We construct a utility-based model of fluctuations, with nominal rigidities and unemployment, and draw its implications for the unemployment-inflation tradeoff and for the conduct of monetary policy.

We proceed in two steps. We first leave nominal rigidities aside. We show that, under a standard utility specification, productivity shocks have no effect on unemployment in the constrained efficient allocation. We then focus on the implications of alternative real wage setting mechanisms for fluctuations in unemployment. We show the role of labor market frictions and real wage rigidities in determining the effects of productivity shocks on unemployment.

We then introduce nominal rigidities in the form of staggered price setting by firms. We derive the relation between inflation and unemployment and discuss how it is influenced by the presence of labor market frictions and real wage rigidities. We show the nature of the tradeoff between inflation and unemploy-
\end{abstract}

* We thank Ricardo Caballero, Pierre Cahuc, Mark Gertler, Marvin Goodfriend, Bob Hall, Dale Henderson, Peter Ireland, Julio Rotemberg, Richard Rogerson, Ivan Werning, and Michael Woodford for helpful comments. We also thank Dan Cao for valuable research assistance. Galí aknowledges the financial support of the Ministerio de Educación y Ciencia (SEJ 2005-01124) and the Barcelona Economics Network.

$\dagger \quad$ MIT and NBER.

$\ddagger \quad$ CREI, Universitat Pompeu Fabra, CEPR and NBER. 
ment stabilization, and its dependence on labor market characteristics. We draw the implications for optimal monetary policy.

JEL Classification: E32, E50.

Keywords: New-Keynesian model, labor market frictions, search model, unemployment, sticky prices, real wage rigidities. 


\section{Introduction}

The New-Keynesian model (the NK model, for short) has emerged as a powerful tool for monetary policy analysis in the presence of nominal rigidities. Its adoption as the backbone of the medium-scale models currently developed by many central banks and policy institutions is a clear reflection of its success. This popularity may be viewed as somewhat surprising given that standard versions of the NK paradigm do not generate movements in unemployment, only voluntary movements in hours of work or employment. ${ }^{1}$

This provides the motivation for our paper. We extend the NK model by introducing a more realistic labor market, with frictions similar to those found in the Diamond-Mortensen-Pissarides search and matching model of unemployment (the DMP model, henceforth). This extension allows us to characterize the effects of productivity shocks on both unemployment and inflation, and to show how these effects depend both on monetary policy and on the nature of labor market frictions. It also allows us to derive optimal monetary policy, and characterize its dependence on labor market frictions, to answer for example how monetary policy should differ, depending on whether, for example, the labor market is fluid - as in the United States - or sclerotic instead - as in Continental Europe.

The paper is organized as follows:

Section 2 sets up the basic model with frictions, leaving out nominal rigidities. We capture labor market frictions through hiring costs increasing in labor market tightness - defined as the ratio of hires to the unemployment pool. We then characterize the constrained-efficient allocation: Frictions lead to unemployment, but the unemployment rate is invariant to productivity shocks. The reason is that, as in the corresponding model without frictions, income and substitution effects cancel, leading to no change in employment, and in unemployment. Frictions do not affect this outcome.

Section 3 characterizes the decentralized equilibrium under alternative wagesetting mechanisms. As is well understood, frictions create a wage band, within

1. Paradoxically, this was viewed as one of the main weaknesses of the RBC model, but was then exported to the NK model. 
which any real wage is consistent with private efficiency. We thus explore two alternatives. We first assume Nash-bargaining. In this case, the unemployment rate is typically different from the constrained-efficient rate, but, like the constrainedefficient rate, it is also invariant to productivity shocks. We then allow for more rigid real wages, and show that in this case, productivity shocks lead to inefficient fluctuations in unemployment. We characterize these fluctuations as a function of the labor market frictions and the degree of real wage rigidity.

Section 4 introduces nominal rigidities, in the form of staggering of price decisions by firms. Productivity shocks now affect both the inflation rate and the unemployment rate. We derive the relation between inflation and unemployment implied by the model, and contrast it to the standard NK formulation. Put crudely, the model implies a relation between inflation and labor market tightness. This in turn implies a relation between inflation and both the level and the change in the unemployment rate.

Section 5 turns to the implications for monetary policy. It shows that stabilizing unemployment in response to productivity shocks requires allowing for transitorily higher inflation. It shows how stabilizing inflation leads to large and inefficient movements in unemployment (recall that constrained-efficient unemployment is constant) . It shows how the persistence of unemployment is higher in more sclerotic markets, i.e. markets in which the separation and the hiring rate are lower. It then derives optimal monetary policy, showing its dependence on labor market characteristics

Section 6 offers two calibrations of the model, one aimed at capturing the United States, the other aimed at capturing continental Europe, with its more sclerotic labor markets. In each case, it presents the implications of pursuing either inflation-stabilizing, unemployment-stabilizing, or optimal monetary policy. We also study the extent to which a simple interest rate rule can approximate the optimal policy outcomes.

Section 7 indicates how our model relates to the existing-and rapidly growingliterature on the relative roles of labor market frictions, real wage rigidities, and nominal price rigidities in shaping fluctuations. This literature started with Mon- 
ica Merz's (1995) integration of labor market frictions in an RBC model, and now encompasses a number of medium size DSGE models with labor market frictions, and real and nominal wage and price rigidities. We see the comparative strength of our paper as being in its simplicity. This simplicity allows for an analytical characterization of fluctuations, and an analytical derivation of optimal policy. It makes clear the separate role of frictions, real wage rigidities, and monetary policy, in mediating the effects of productivity shocks on inflation and unemployment.

Section 8 concludes.

\section{$2 \quad$ The Basic Model}

\section{$2.1 \quad$ Assumptions}

\section{Preferences}

The representative household is made up of a continuum of members represented by the unit interval. The household maximizes

$$
E_{0} \sum \beta^{t}\left(\log C_{t}-\chi \frac{N_{t}^{1+\phi}}{1+\phi}\right)
$$

where $C_{t}$ is a CES function over a continuum of goods with elasticity of substitution $\epsilon$, and $N_{t}$ denotes the fraction of household members who are employed. The latter must satisfy the constraint

$$
0 \leq N_{t} \leq 1
$$

Note that such a specification of utility differs from the one generally used in the DMP model, where the marginal rate of substitution is assumed to be constant. Our specification is, instead, one often used in models of the business cycle, given its consistency with a balanced growth path and the direct parametrization of the inverse of the Frisch labor supply elasticity by $\phi$. 


\section{Technology}

We assume a continuum of firms indexed by $i \in[0,1]$, each producing a differentiated final good. All firms have access to an identical technology

$$
Y_{t}(i)=X_{t}(i)
$$

where $X_{t}(i)$ is the quantity of the (single) intermediate good.

The latter is produced by a large number of identical, perfectly competitive firms, indexed by $j \in[0,1]$, and with a production function ${ }^{2}$

$$
X_{t}(j)=A_{t} N_{t}(j)
$$

Variable $A_{t}$ represents the state of technology, which is assumed to be common across firms and to vary exogenously over time.

Employment in firm $j$ evolves according to

$$
N_{t}(j)=(1-\delta) N_{t-1}(j)+H_{t}(j)
$$

where $\delta \in(0,1)$ is an exogenous separation rate, and $H_{t}(j)$ represents the measure of workers hired by firm $j$ in period $t$. Note that new hires start working in the period they are hired.

\section{Labor Market}

Flows and Timing.

At the beginning of period $t$ there is a pool of jobless individuals who are available for hire, and whose size we denote by $U_{t}$. We refer to the latter variable as beginning-of-period unemployment (or just unemployment, for short). We make assumptions below that guarantee full participation, i.e. at all times all individuals are either employed or willing to work, given the prevailing labor market

2. The motivation for the separation between final goods producers with monopoly power and perfectly competitive intermediate good producers is to avoid interactions between price setting and wage bargaining at the firm level. 
conditions. Accordingly, we have

$$
U_{t}=1-N_{t-1}+\delta N_{t-1}=1-(1-\delta) N_{t-1}
$$

Among those unemployed at the beginning of period $t$, a measure $H_{t} \equiv \int_{0}^{1} H_{t}(j) d j$ are hired and start working in the same period. Aggregate hiring evolves according to

$$
H_{t}=N_{t}-(1-\delta) N_{t-1}
$$

where $N_{t} \equiv \int_{0}^{1} N_{t}(j) d j$ denotes aggregate employment.

We introduce an index of labor market tightness, $x_{t}$, which we define as the ratio of aggregate hires to unemployment

$$
x_{t} \equiv \frac{H_{t}}{U_{t}}
$$

This tightness index $x_{t}$ will play a central role in what follows. It is assumed to lie within the interval $[0,1]$. Only workers in the unemployment pool at the beginning of the period can be hired $\left(H_{t} \leq U_{t}\right)$.

Note that, from the viewpoint of the unemployed, the index $x_{t}$ has an alternative interpretation: It is the probability of being hired in period $t$, or, in other words, the job-finding rate. Below we use the terms labor market tightness and jobfinding rate interchangeably.

Hiring costs.

Hiring labor is costly. Hiring costs for an individual firm are given by $G_{t} H_{t}(j)$, expressed in terms of the CES bundle of goods. $G_{t}$ represents the cost per hire, which is independent of $H_{t}(j)$ and taken as given by each individual firm.

While $G_{t}$ is taken as given by each firm, it is an increasing function of labor market tightness. Formally, we assume

$$
G_{t}=A_{t} B x_{t}^{\alpha}
$$


where $\alpha \geq 0$ and $B$ is a positive constant. ${ }^{3}$ It is convenient, for later use, to define $g_{t} \equiv B x_{t}^{\alpha}$, so $G_{t}=A_{t} g_{t}$.

Note that, under our formalization, vacancies are assumed to be filled immediately by paying the hiring cost, which is a function of labor market tightness. By contrast, in the DMP model, the hiring cost is uncertain, with its expected value corresponding to the (per period) cost of posting a vacancy times the expected time to fill it. This expected time is an increasing function of the ratio of vacancies to unemployment, which can be expressed in turn as a function of labor market tightness. Thus, while the formalism used to capture the presence of hiring costs is different, both approaches share the basic characteristic that the cost of hiring is increasing in labor market tightness.

Finally, it is useful, for future reference, to define an alternative measure of unemployment, denoted by $u_{t}$, and given by the fraction of the population who are left without a job after hiring takes place in period $t$. Formally, and given our assumption of full participation, we have

$$
u_{t}=1-N_{t}
$$

\subsection{The Constrained-Efficient Allocation}

We derive the constrained-efficient allocation by solving the problem of a benevolent social planner who faces the technological constraints and labor market frictions that are present in the decentralized economy. The social planner, however, internalizes the effect of variations in labor market tightness on hiring costs and, hence, on the resource constraint.

Given symmetry in preferences and technology, efficiency requires that identical quantities of each good be produced and consumed, i.e. $C_{t}(i)=C_{t}$ for all $i \in[0,1]$. Furthermore, since labor market participation has no individual cost but some social benefit (it lowers hiring costs, for any given level of employment and hiring),

3. The motivation for the presence of $A_{t}$ in the expression for $G_{t}$ is to avoid effects of productivity shocks on the cost of hiring relative to the cost of producing, an effect we believe is best left out of the model. 
the social planner will always choose an allocation with full participation (though not necessarily full employment, since higher employment generates disutility and raises hiring costs).

Hence the social planner maximizes (1) subject to (2) and the aggregate resource constraint

$$
C_{t}=A_{t}\left(N_{t}-B x_{t}^{\alpha} H_{t}\right)
$$

where $H_{t}$ and $x_{t}$ are defined in (4) and (5).

The optimality condition for the planner's problem can be written as

$$
\begin{aligned}
C_{t} N_{t}^{\phi} \leq & A_{t}-(1+\alpha) A_{t} B x_{t}^{\alpha} \\
& +\beta(1-\delta) E_{t}\left\{\frac{C_{t}}{C_{t+1}} A_{t+1} B x_{t+1}^{\alpha}\left(1+\alpha\left(1-x_{t+1}\right)\right)\right\}
\end{aligned}
$$

which holds with equality if $N_{t}<1$. Henceforth, we restrict our analysis (both of the social planner's problem and the equilibrium) to allocations characterized by $N_{t} \in(0,1)$ for all $t$ (and, hence, positive unemployment).

Note that the left-hand side of (7) represents the marginal rate of substitution between labor and consumption, whereas the right-hand side captures the corresponding marginal rate of transformation. The latter has two components: The first component corresponds to the additional output, net of hiring costs, generated by a marginal employed worker. The second captures the savings in hiring costs resulting from the reduced hiring needs in period $t+1 .{ }^{4}$

The solution to this equation is easy to characterize:

- $\quad$ Consider first the case where labor market frictions are absent (i.e. $B=$ $0)$. In that case we have $C_{t}=A_{t} N_{t}$, and the equilibrium condition (7)

4. Note that hiring costs (normalized by productivity) at time $t$ are given by $B x_{t}^{\alpha} H_{t}$. The term $B x_{t}^{\alpha}$ in (7) captures the increase in hiring costs resulting from an additional hire, keeping cost per hire unchanged. The term $\alpha B x_{t}^{\alpha}$ reflects the effect on hiring costs of the change in the tightness index $x_{t}$ induced by an additional hire (given $H_{t}$ ). The savings in hiring costs at $t+1$ also have two components, both of which are proportional to $1-\delta$, the decline in required hiring. The first component, $B x_{t+1}^{\alpha}$, captures saving resulting from a lower $H_{t+1}$, given cost per hire. The (negative) term $\alpha B x_{t}^{\alpha}\left(1-x_{t+1}\right)$ adjusts the first component to take into account the lower cost per hire brought about by a smaller $x_{t+1}$ (the effect of lower required hires, $H_{t+1}$, more than offsetting the smaller unemployment pool, $\left.U_{t+1}\right)$. 
simplifies to

$$
\chi N_{t}^{1+\phi}=1
$$

if $\chi \geq 1$, or $N_{t}=1$ if $\chi<1$. In either case, the constrained-efficient allocation implies a level of employment invariant to productivity shocks. This invariance is the result of offsetting income and substitution effects on labor supply. Absent capital accumulation, consumption increases in proportion to productivity; given a specification of preferences consistent with balanced growth, this increase in consumption leads to an income effect that exactly offsets the substitution effect.

When labor market frictions are present (i.e. $B>0$ ), the solution to (7) involves a constant job finding rate $x^{*}$, which, assuming an interior solution, is implicitly determined by

$$
\left(1-\delta B x^{\alpha}\right) \chi N(x)^{1+\phi}=1-(1-\beta(1-\delta))(1+\alpha) B x^{\alpha}-\beta(1-\delta) \alpha B x^{1+\alpha}
$$

where $N(x) \equiv \frac{x}{\delta+(1-\delta) x}$ is the level of employment given $x$. Thus, the constrained-efficient allocation implies a constant unemployment rate given by: ${ }^{5}$

$$
u=\frac{\delta\left(1-x^{*}\right)}{\delta+(1-\delta) x^{*}}
$$

The implied levels of consumption and output are proportional to productivity, and given by $C_{t}^{*}=A_{t} N^{*}\left(1-\delta B x^{* \alpha}\right)$ and $Y_{t}^{*}=A_{t} N^{*}$.

Thus, the equilibrium inherits the main property of the equilibrium without frictions, namely the invariance of employment to productivity shocks. It does so because, at an unchanged employment level, both the marginal rate of substitution and the (social) marginal rate of transformation increase in the same proportion as productivity, given our assumptions on preferences and technology.

5. The condition for an interior solution to (9) is that the marginal rate of substitution be greater than the (social) marginal rate of transformation, both evaluated at full employment (i.e. evaluated at $N=1, x=1, H=\delta$ ):

$$
\chi(1-\delta B)>1-(1+\alpha-\beta(1-\delta)) B
$$


This invariance result is obviously a special one (e.g. it would no longer hold if we introduced capital accumulation). It is, however, very convenient for our purposes, since it establishes a simple benchmark. And it contains a more general lesson. Even in a model with labor market frictions, the behavior of the marginal rate of substitution remains central to the outcome.

The next step is to characterize the equilibrium in the decentralized economy. We consider first the case of flexible prices, leaving the introduction of price rigidities to the following section.

\section{Equilibrium Under Flexible Prices}

\subsection{Price setting}

Let $P_{t}$ be the price level (the price index associated with $C_{t}$ ), $P_{t}^{I}$ be the price of the intermediate good, and $W_{t}$ be the real wage (the wage in terms of the bundle of final consumption goods).

Intermediate goods firms take the price of their good as given. Profit maximization requires that the following condition be satisfied for all $t$ :

$$
\left(\frac{P_{t}^{I}}{P_{t}}\right) A_{t}=W_{t}+G_{t}-\beta(1-\delta) E_{t}\left\{\frac{C_{t}}{C_{t+1}} G_{t+1}\right\}
$$

Note that the left-hand side represents the real marginal revenue product of labor, while the right-hand side denotes the real marginal cost (including the component associated with hiring costs).

Profit maximization by final goods firms requires $P_{t}=\mathcal{M} P_{t}^{I}$ for all $t$, where $\mathcal{M} \equiv \frac{\epsilon}{\epsilon-1}$ is the optimal gross markup. Replacing in (10) and reorganizing gives

$$
B x_{t}^{\alpha}=\left(\frac{1}{\mathcal{M}}-\frac{W_{t}}{A_{t}}\right)+\beta(1-\delta) E_{t}\left\{\frac{C_{t}}{C_{t+1}} \frac{A_{t+1}}{A_{t}} B x_{t+1}^{\alpha}\right\}
$$

Solving (11) forward, it follows that the rate at which labor is hired, and hence labor market tightness, depends on the expected discounted stream of marginal 
profits generated by an additional hire. Marginal profit depends in turn on the ratio of the wage to productivity.

Next we turn to wage determination. The presence of labor market frictions generates a surplus associated with established employment relationships. The wage determines how that surplus is split between workers and firms. We consider two alternative wage-determination regimes.

\subsection{Nash-Bargained Wages}

The first regime, following much of the literature, is Nash bargaining. Note that the value of an employed member to a household, denoted by $\mathcal{V}_{t}^{N}$, is given by

$$
\mathcal{V}_{t}^{N}=W_{t}-\chi C_{t} N_{t}^{\varphi}+\beta E_{t}\left\{\frac{C_{t}}{C_{t+1}}\left[\left(1-\delta\left(1-x_{t+1}\right)\right) \mathcal{V}_{t+1}^{N}+\delta\left(1-x_{t+1}\right) \mathcal{V}_{t+1}^{U}\right]\right\}
$$

where $\mathcal{V}_{t}^{U}$ is the value of an unemployed member, given in turn by

$$
\mathcal{V}_{t}^{U}=\beta E_{t}\left\{\frac{C_{t}}{C_{t+1}}\left[x_{t+1} \mathcal{V}_{t+1}^{N}+\left(1-x_{t+1}\right) \mathcal{V}_{t+1}^{U}\right]\right\}
$$

It follows that the household's surplus from an established employment relationship, $\mathcal{S}_{t}^{H} \equiv \mathcal{V}_{t}^{N}-\mathcal{V}_{t}^{U}$, can be written as

$$
\mathcal{S}_{t}^{H}=W_{t}-\chi C_{t} N_{t}^{\varphi}+\beta(1-\delta) E_{t}\left\{\frac{C_{t}}{C_{t+1}}\left(1-x_{t+1}\right) \mathcal{S}_{t+1}^{H}\right\}
$$

On the other hand, the firm's surplus from an established employment relationship, denoted by $\mathcal{S}_{t}^{F}$, is simply given by

$$
\mathcal{S}_{t}^{F}=A_{t} B x_{t}^{\alpha}
$$

since any current worker can be immediately replaced with someone who is unemployed by paying the hiring cost, $G_{t}$.

The Nash bargain must satisfy

$$
\mathcal{S}_{t}^{H}=\vartheta \mathcal{S}_{t}^{F}
$$


where $\vartheta$ represents the relative bargaining power of workers. Combining this condition with (12) and (13), yields the following wage schedule

$$
W_{t}=\chi C_{t} N_{t}^{\varphi}+\vartheta\left(A_{t} B x_{t}^{\alpha}-\beta(1-\delta) E_{t}\left\{\frac{C_{t}}{C_{t+1}}\left(1-x_{t+1}\right) A_{t+1} B x_{t+1}^{\alpha}\right\}\right)
$$

The bargained wage is equal to the marginal rate of substitution plus - to the extent that workers have some bargaining power $(\vartheta>0)$ and labor market frictions are present $(B>0)$ - an additional term reflecting labor market conditions. This term is increasing in current labor market tightness $x_{t}$ (since this raises the firm's surplus associated with an existing relationship) and decreasing in expected future hiring costs, $A_{t+1} B x_{t+1}^{\alpha}$, and the probability of not finding a job if unemployed next period, $\left(1-x_{t+1}\right)$, since those raise the continuation value to an employed worker, thus reducing the required wage today.

Equation (11) implicitly gives the wage consistent with price setting. Equation (14) gives the wage consistent with Nash bargaining. Combining the two gives the equilibrium condition

$$
\chi C_{t} N_{t}^{\phi}=\frac{A_{t}}{\mathcal{M}}-(1+\vartheta) A_{t} B x_{t}^{\alpha}+\beta(1-\delta) E_{t}\left\{\frac{C_{t}}{C_{t+1}} A_{t+1}\left(1+\vartheta\left(1-x_{t+1}\right)\right) B x_{t+1}^{\alpha}\right\}
$$

It can easily be checked that the equilibrium implies again a constant job finding rate $x$, given implicitly by the solution to

$$
\left(1-\delta B x^{\alpha}\right) \chi N(x)^{1+\phi}=\frac{1}{\mathcal{M}}-(1-\beta(1-\delta))(1+\vartheta) B x^{\alpha}-\beta(1-\delta) \vartheta B x^{1+\alpha}
$$

where, as before, $N(x) \equiv \frac{x}{\delta+(1-\delta) x} \cdot{ }^{6}$ This, in turn, implies a constant unemployment rate

$$
u=\frac{\delta(1-x)}{\delta+(1-\delta) x}
$$

6. The condition for an interior solution is now given by

$$
\chi(1-\delta B)>\frac{1}{\mathcal{M}}-(1+\vartheta-\beta(1-\delta)) B
$$


Consumption, output, and the real wage all vary in proportion to productivity. In particular, the real wage is given by

$$
W_{t}=\left(\frac{1}{\mathcal{M}}-(1-\beta(1-\delta)) B x^{\alpha}\right) A_{t}
$$

The condition for full participation is given by $W_{t}>\chi C_{t}$ for all $t$, since $\chi C_{t}$ corresponds to the marginal rate of substitution evaluated at "full employment" (i.e. at $N_{t}=1$ ). Under our assumption that wages are Nash-bargained, so employment is constant, this condition reduces to $\left(\frac{1}{\mathcal{M}}-(1-\beta(1-\delta)) g\right)>\chi N(x)(1-\delta g)$. We shall assume that this condition holds throughout (and verify that it is the case for the calibrations below).

Note the two main characteristics of the equilibrium with Nash-bargained wages:

The equilibrium unemployment rate generally differs from the constrained-efficient rate. Comparing (9) and (16) shows that the two unemployment rates coincide if

$$
\mathcal{M}=1 \text { and } \vartheta=\alpha
$$

i.e. in the absence of effective market power by final goods firms, and when the relative bargaining power of workers matches the elasticity of hiring costs relative to the labor market tightness index - a Hosios-like condition, familiar from DMP models.

Whether or not the equilibrium unemployment rate is equal to the constrainedefficient rate, it shares however its property that it is invariant to productivity shocks. The source of the invariance again comes from the offsetting income and substitution effects, leading to a one-for-one response of the wage to productivity, and resulting in constant employment and unemployment rates.

This invariance result is different from the Shimer puzzle, the argument by Shimer (2005) that the DMP model implies small movements in unemployment in response to movements in productivity. To see how the two results are related, return to the wage schedule under Nash bargaining, equation (14). Shimer's result was derived under the assumption that the first term - the marginal rate of 
substitution - was constant. He then argued that, under reasonable values of the parameters characterizing labor market frictions, the second term - the term due to frictions - was likely to imply large movements in wages in response to productivity, and, by implication, small movements in profit, job creation, employment, and unemployment. In contrast, our neutrality result follows entirely from movements in the marginal rate of substitution. Under our assumptions, the marginal rate of substitution moves one-for-one with productivity, so employment does not change, and labor market frictions have no role to play. It is clear that, under more general assumptions (for example in models where consumption increases less than one-for-one with productivity, because of the presence of investment), both the marginal rate of substitution and labor market frictions will determine the wage response. Because the marginal rate of substitution is likely to increase with productivity (although not necessarily one-for-one as it does here), the wage response will be stronger than in the DMP model. Put another way, the Shimer puzzle will be even stronger than in the original Shimer set-up.

This large response of the wage to productivity movements appears counterfactual. This has led several authors to introduce some form of real wage rigidity in order to match the small movements in the wage and the large movements in unemployment. ${ }^{7}$ Following their lead, the next subsection introduces wage rigidity, and analyzes its implications for equilibrium unemployment.

\subsection{Real Wage Rigidities}

As emphasized by Hall (2005), the presence of a surplus associated with existing relations implies that many wages may be consistent with equilibrium. More specifically, existing employment relationships will be privately efficient so long as they generate a positive surplus to both parties involved. Thus, and using the notation introduced in the previous subsection, any wage path such that $\mathcal{S}_{t}^{H} \geq 0$ and $\mathcal{S}_{t}^{F} \geq 0$ for all $t$ is consistent with equilibrium. Nash-bargaining generates only one such path.

7. See Shimer (2005), Hall (2005), and Gertler and Trigari (2006). For a view that such rigidities may not be needed, see Hagedorn and Manovskii (2006). 
In the context of our model, a sufficient condition for $\mathcal{S}_{t}^{H} \geq 0$ is given by $W_{t} \geq$ $\chi C_{t} N_{t}^{\phi}$ for all $t$, which is in turn already implied by the full participation condition $W_{t} \geq \chi C_{t}$. On the other hand, a sufficient condition for $\mathcal{S}_{t}^{F} \geq 0$ is given by $W_{t} \leq \frac{P_{t}^{I}}{P_{t}} A_{t}=\frac{A_{t}}{\mathcal{M}}$ for all $t$, i.e. the existence of non-negative profits (gross of hiring costs) for intermediate goods firms. It follows that any wage path satisfying

$$
\chi C_{t} \leq W_{t} \leq \frac{A_{t}}{\mathcal{M}}
$$

for all $t$ is consistent with equilibrium. Note that, under our assumptions, the previous condition is satisfied when the wage is determined through Nash bargaining. In what follows, we shall assume the economy fluctuates in a neighborhood of the steady state under Nash bargaining. In that case, and to the extent that shocks are not too large, the previous condition will also be satisfied.

How to formalize real wage rigidity is still very much an open research question. To keep the analysis as simple as possible, we assume a wage schedule of the form

$$
W_{t}=\Theta A_{t}^{1-\gamma}
$$

where $\gamma \in[0,1]$ is an index of real wage rigidities, and $\Theta$ is a positive constant.

Clearly, the above formulation is meaningful only if technology is stationary, an assumption we shall maintain here. Denoting the unconditional mean of $A_{t}$ by $A$, we assume that $\Theta \equiv\left(\frac{1}{\mathcal{M}}-(1-\beta(1-\delta)) B x^{\alpha}\right) A^{\gamma}$. This implies that the mean wage coincides with the mean wage under Nash-bargaining. Note then that for $\gamma=0$, the wage corresponds exactly to the equilibrium wage under Nash bargaining (as given by (17)). At the other extreme, when $\gamma=1$, equation (18) corresponds to the canonical example of a rigid wage analyzed by Hall (2005).

Combining the wage equation (18) with the equation for the wage implied by price setting, equation (11), gives us the equation for the equilibrium under real wage rigidity.

$$
\Theta A_{t}^{-\gamma}=\frac{1}{\mathcal{M}}-B x_{t}^{\alpha}+\beta(1-\delta) E_{t}\left\{\frac{C_{t}}{C_{t+1}} \frac{A_{t+1}}{A_{t}} B x_{t+1}^{\alpha}\right\}
$$


Rearranging, and solving forward yields

$$
B x_{t}^{\alpha}=\sum_{k=0}^{\infty}(\beta(1-\delta))^{k} E_{t}\left\{\Lambda_{t, t+k}\left(\frac{1}{\mathcal{M}}-\Theta A_{t+k}^{-\gamma}\right)\right\}
$$

where $\Lambda_{t, t+k} \equiv\left(C_{t} / C_{t+k}\right)\left(A_{t+k} / A_{t}\right)$.

The previous equation makes clear the central role of labor market tightness $x_{t}$ in this economy with labor market frictions and rigid real wages. As long as wages are not fully flexible $(\gamma>0)$, labor market tightness, and, by implication, movements in employment and in unemployment, depend on current and anticipated productivity. Shimer (2005), Hall (2005), and the research which has followed their two articles, studied the implications of equations similar to (20) for fluctuations in wages, employment, and unemployment in response to productivity shocks. By contrast, our goal here is to study the implications in an economy with nominal rigidities, and the role for monetary policy. To do so, we need to introduce price stickiness. This is what we do in the next section.

\section{$4 \quad$ Introducing Nominal Rigidities}

Following much of the recent literature on monetary business cycle models, we introduce sticky prices in our model with labor market frictions using the formalism due to Calvo (1983). Each period, only a fraction $1-\theta$ of the final goods producers, selected randomly, reset prices. The remaining final goods producers, with measure $\theta$, keep their prices unchanged. Thus, the aggregate price level satisfies

$$
P_{t}=\left((1-\theta)\left(P_{t}^{*}\right)^{1-\epsilon}+\theta\left(P_{t-1}\right)^{1-\epsilon}\right)^{\frac{1}{1-\epsilon}}
$$

where $P_{t}^{*}$ denotes the price newly set by a final goods producer at time $t$.

The optimal price setting rule for a firm resetting prices in period $t$ is given by

$$
E_{t}\left\{\sum_{k=0}^{\infty} \theta^{k} Q_{t, t+k} Y_{t+k \mid t}\left(P_{t}^{*}-\mathcal{M} P_{t+k} M C_{t+k}\right)\right\}=0
$$


where $P_{t}^{*}$ denotes the price newly set by at time $t, Y_{t+k \mid t}$ is the level of output in period $t+k$ for a firm resetting its price in period $t, \mathcal{M} \equiv \frac{\epsilon}{\epsilon-1}$ is the gross desired markup, and $M C_{t}$ is the real marginal cost for final goods producers.

Real marginal cost is turn given by $P_{t}^{I} / P_{t}$. Under the maintained assumption of flexible prices in the market for intermediate goods, so, using equation (10) for the price of intermediate goods, and equation (18) for wage setting, real marginal cost is given by

$$
M C_{t}=\Theta A_{t}^{-\gamma}+B x_{t}^{\alpha}-\beta(1-\delta) E_{t}\left\{\frac{C_{t}}{C_{t+1}} \frac{A_{t+1}}{A_{t}} B x_{t+1}^{\alpha}\right\}
$$

Equations (22) and (23) embody the essence of our framework:

- $\quad$ The optimal price setting equation (22) takes the same form as in the standard Calvo model, given the path of marginal costs: It leads firms to choose a price that is a weighted average of current and expected marginal costs, with the weights being a function of $\theta$, the price stickiness parameter.

- The marginal cost in equation (23) depends on labor market frictions (as captured by hiring cost parameters $B$ and $\alpha$ ) and on real wage rigidities (measured by $\gamma$ ).

To make progress requires log-linearizing the system, the task to which we now turn.

\subsection{Log-linearized Equilibrium Dynamics}

Let lower case variables with hats denote log deviations of the corresponding upper case variables from their steady state values.

- $\quad$ From equations (21) and (22), we get, after log-linearization around a zero inflation steady state, an expression for inflation ${ }^{8}$

$$
\pi_{t}=\beta E_{t}\left\{\pi_{t+1}\right\}+\lambda \widehat{m c}_{t}
$$

8. See, e.g., Galí and Gertler (1999) for a derivation. 
where $\lambda \equiv(1-\beta \theta)(1-\theta) / \theta$.

- From equation (23), we get an expression for marginal cost,

$\widehat{m c}_{t}=\alpha g \mathcal{M} \widehat{x}_{t}-\beta(1-\delta) g \mathcal{M} E_{t}\left\{\left(\widehat{c}_{t}-\widehat{a}_{t}\right)-\left(\widehat{c}_{t+1}-\widehat{a}_{t+1}\right)+\alpha \widehat{x}_{t+1}\right\}-\Phi \gamma \widehat{a}_{t}$

where $\Phi \equiv \mathcal{M} W / A=1-(1-\beta(1-\delta)) g \mathcal{M}<1$.

- From equation (5), we get an expression for labor market tightness as a function of current and lagged employment

$$
\delta \widehat{x}_{t}=\widehat{n}_{t}-(1-\delta)(1-x) \widehat{n}_{t-1}
$$

- $\quad$ From equation (6), we get an expression for consumption

$$
\widehat{c}_{t}=\widehat{a}_{t}+\frac{1-g}{1-\delta g} \widehat{n}_{t}+\frac{g(1-\delta)}{1-\delta g} \widehat{n}_{t-1}-\frac{\alpha g}{1-\delta g} \delta \widehat{x}_{t}
$$

- From the first order conditions of the consumer (which we have ignored until now), we get:

$$
\widehat{c}_{t}=E_{t}\left\{\widehat{c}_{t+1}\right\}-\left(i_{t}-E_{t}\left\{\pi_{t+1}\right\}-\rho\right)
$$

where $\rho \equiv-\log \beta$.

The equilibrium is characterized by equations (24) to (28), together with a process for productivity and a description of monetary policy.

\subsection{Unemployment and Inflation}

Before we turn to the analysis of alternative policies using the previous equilibrium conditions, we focus on the "Phillips curve" relation between unemployment and inflation implied by our model.

In order to facilitate intuition (and only in this subsection), we do so under two approximations. The first is that hiring costs are small relative to output $(g$ is small), so we can approximate consumption by $\widehat{c}_{t}=\widehat{a}_{t}+\widehat{n}_{t}$, and by implication, 
we can approximate $\left(\widehat{c}_{t}-\widehat{a}_{t}\right)-\left(\widehat{c}_{t+1}-\widehat{a}_{t+1}\right)$ in equation (25) by $\widehat{n}_{t}-\widehat{n}_{t+1}$. The second is that the separation rate, $\delta$, is small, so, from equation (26), fluctuations in $\widehat{x}_{t}$ are large relative to those in $\widehat{n}_{t}$. This in turn implies that we can ignore the terms $\widehat{n}_{t}-\widehat{n}_{t+1}$ in equation (25). Using these two approximations, and the fact that, if $\delta$ is small, $\beta(1-\delta) \approx \beta$, equation (25) can be approximated by:

$$
\widehat{m c}_{t}=\alpha g \mathcal{M}\left(\widehat{x}_{t}-\beta E_{t}\left\{\widehat{x}_{t+1}\right\}\right)-\Phi \gamma \widehat{a}_{t}
$$

Combining equation (29) and equation (24) then gives us a relation between inflation, labor market tightness, and productivity:

$$
\pi_{t}=\alpha g \mathcal{M} \lambda \widehat{x}_{t}-\lambda \Phi \gamma \sum_{k=0}^{\infty} \beta^{k} E_{t}\left\{\widehat{a}_{t+k}\right\}
$$

Note that, despite the fact that expected inflation does not appear in (30), inflation is a forward looking variable, through its dependence on current and future $a_{t}$ 's, and current $x_{t}$, which itself depends on current and expected real marginal costs. $^{9}$

Using equation (26), letting $\widehat{u}_{t} \equiv u_{t}-u$ denote the deviation (not the log deviation) of the unemployment rate (after hiring) from its steady state value, and using the approximation $\widehat{u}_{t}=-(1-u) \widehat{n}_{t}$, gives us in turn a relation between labor market tightness and the unemployment rate:

$$
(1-u) \delta \widehat{x}_{t}=-\widehat{u}_{t}+(1-x)(1-\delta) \widehat{u}_{t-1}
$$

The relation of labor market tightness to current and lagged unemployment will play an important role in what follows. To see what it implies, consider two labor markets. One, with high values of both $\delta$ and $x$, so with high flows and low unemployment duration, which we shall call "fluid." We think of that characterization as capturing the U.S. labor market. The other, with low values of $\delta$ and $x$, so with low flows and high unemployment duration, which we shall call "sclerotic"

9. This can be seen by solving (29) forward, to get $\alpha g \mathcal{M} \widehat{x}_{t}=\sum_{k=0}^{\infty} \beta^{k} E_{t}\left\{\widehat{m c}_{t+k}+\Phi \gamma a_{t+k}\right\}$. 
and think of as capturing continental European labor markets. In the fluid labor market, $(1-x)(1-\delta)$ is small, so relative labor market tightness moves with the (negative) of the unemployment rate. In the sclerotic labor market, $(1-x)(1-\delta)$ is large, so relative labor market tightness moves more with the (negative) of the change in the unemployment rate. The intuition is as follows: In a fluid labor market, average flows are high and, given the constant separation rate, depend on the level of employment rate (equivalently, on the level of unemployment). Changes in employment (equivalently, changes in unemployment) lead to small relative changes in the flows, thus to small relative changes in labor market tightness. In a sclerotic labor market, average flows are low. Changes in employment (equivalently, in unemployment) lead to large relative changes in the flows. Thus, relative labor market tightness depends more on the change in employment (equivalently, on the change in unemployment).

Putting equations (30) and (31) together gives the relation between inflation and unemployment implied by our model. Assume, for simplicity, that productivity follows a stationary $\mathrm{AR}(1)$ process with autoregressive parameter $\rho_{a} \in[0,1)$. We can then rewrite (30) as

$$
\pi_{t}=\alpha g \mathcal{M} \lambda \widehat{x}_{t}-\Psi \gamma \widehat{a}_{t}
$$

where $\Psi \equiv \lambda \Phi /\left(1-\beta \rho_{a}\right)>0$. Thus, inflation depends positively on labor market tightness, and negatively (if $\gamma>0$ ) on productivity. The higher the degree of real wage rigidity, or the more persistent the productivity process, the larger the effect of productivity on inflation.

Replacing market tightness by its expression from equation (31) gives:

$$
\pi_{t}=-\kappa \widehat{u}_{t}+\kappa(1-\delta)(1-x) \widehat{u}_{t-1}-\Psi \gamma \widehat{a}_{t}
$$

where $\kappa \equiv \alpha g \mathcal{M} \lambda / \delta(1-u)$. Or equivalently

$$
\pi_{t}=-\kappa(1-(1-\delta)(1-x)) \widehat{u}_{t}-\kappa(1-\delta)(1-x) \Delta \widehat{u}_{t}-\Psi \gamma \widehat{a}_{t}
$$

which highlights the negative dependence of inflation on both the level and the 
change in the unemployment rate, with the weights attached to each being a function of the degree of fluidity of the labor market: The more sclerotic the labor market, the weaker the effect of the level of unemployment, and the stronger the effect of the change in unemployment.

Given that the constrained-efficient unemployment is constant, it would be best to stabilize both unemployment and inflation. Note however that, to the extent that the wage does not adjust fully to productivity changes $(\gamma>0)$, it is not possible for the monetary authority to fully stabilize both unemployment and inflation simultaneously. There is, to use the terminology introduced by Blanchard and Gali (2007), no divine coincidence. The reason is the same as in our earlier paper, the fact that productivity shocks affect the wedge between the natural rate - the unemployment rate that would prevail absent nominal rigidities - and the constrained-efficient unemployment rate. Stabilizing inflation, which is equivalent to stabilizing unemployment at its natural rate, does not deliver constant unemployment. Symmetrically, stabilizing unemployment does not deliver constant inflation.

The next two sections examine the implications of alternative monetary policy regimes, both qualitative and quantitative. In doing so, we go back to the "exact" log-linearized model, characterized earlier.

\section{$5 \quad$ Unemployment, Inflation, and Monetary Policy}

To characterize the effects of monetary policy, we must first derive the exact version of the Phillips curve. Note first that combining (26) and (27) we obtain

$$
\widehat{c}_{t}=\widehat{a}_{t}+\xi_{0} \widehat{n}_{t}+\xi_{1} \widehat{n}_{t-1}
$$

where $\xi_{0} \equiv \frac{1-g(1+\alpha)}{(1-\delta g)}$ and $\xi_{1} \equiv \frac{g(1-\delta)(1+\alpha(1-x))}{(1-\delta g)}$. Replacing this expression, together with (31), into (25) gives an expression for marginal cost:

$$
\widehat{m c}_{t}=h_{0} \widehat{n}_{t}+h_{L} \widehat{n}_{t-1}+h_{F} E_{t}\left\{\widehat{n}_{t+1}\right\}-\Phi \gamma \widehat{a}_{t}
$$


where

$$
\begin{aligned}
h_{0} & \equiv(\alpha g \mathcal{M} / \delta)\left(1+\beta(1-\delta)^{2}(1-x)\right)+\beta(1-\delta) g \mathcal{M}\left(\xi_{1}-\xi_{0}\right) \\
h_{L} & \equiv-(\alpha g \mathcal{M} / \delta)(1-\delta)(1-x)-\beta(1-\delta) g \mathcal{M} \xi_{1} \\
h_{F} & \equiv-\beta(1-\delta) g \mathcal{M}\left((\alpha / \delta)-\xi_{0}\right)
\end{aligned}
$$

Replacing real marginal cost in equation (24) by the expression above, and using the fact that $\widehat{u}_{t}=-(1-u) \widehat{n}_{t}$, gives the following Phillips curve relation between inflation to unemployment:

$$
\pi_{t}=\beta E_{t}\left\{\pi_{t+1}\right\}-\kappa_{0} \widehat{u}_{t}+\kappa_{L} \widehat{u}_{t-1}+\kappa_{F} E_{t}\left\{\widehat{u}_{t+1}\right\}-\lambda \Phi \gamma \widehat{a}_{t}
$$

where $\kappa_{0} \equiv \lambda h_{0} /(1-u), \kappa_{L} \equiv-\lambda h_{L} /(1-u)$, and $\kappa_{F} \equiv \lambda h_{F} /(1-u)$.

\subsection{Two Extreme Policies}

We start by discussing two simple, but extreme, policies and their outcomes for inflation and unemployment.

Unemployment stabilization. Recall that in the constrained efficient allocation unemployment is constant. A policy that seeks to stabilize the gap between unemployment and its efficient level requires therefore that $\widehat{u}_{t}=0$ for all $t$ (and, hence, $\widehat{n}_{t}=\widehat{x}_{t}=0$ for all $t$ as well). Thus, it follows from (34) that

$$
\pi_{t}=-\Psi \gamma \widehat{a}_{t}
$$

where, as above, $\Psi \equiv \lambda \Phi /\left(1-\beta \rho_{a}\right)>0$. The stabilization of unemployment (and thus of hiring costs) makes the real marginal cost vary negatively with productivity, according to $\hat{m} c_{t}=-\Psi \gamma a_{t}$, generating fluctuations in inflation. The amplitude of those fluctuations is increasing in the degree of wage rigidities $\gamma(\Psi$ does not depend on $\gamma)$, and in the persistence of the productivity process, $\rho_{a}$, but is decreasing in the degree of nominal rigidities (which is inversely related to $\lambda)$.

Strict inflation targeting. As (24) makes clear, setting $\pi_{t}=0$ for all $t$ requires 
that real marginal cost be fully stabilized, i.e. $\widehat{m c}_{t}=0$ for all $t$. Given that variations in productivity are not fully offset by a proportional adjustment in the wage, stabilizing the real marginal cost requires that unemployment (and, with it, hiring costs) varies negatively with productivity. Imposing $\pi_{t}=0$ for all $t$ in (34) yields the following difference equation for unemployment:

$$
\widehat{u}_{t}=d_{L} \widehat{u}_{t-1}+d_{F} E_{t}\left\{\widehat{u}_{t+1}\right\}-d_{a} \widehat{a}_{t}
$$

where $d_{L} \equiv \kappa_{L} / \kappa_{0}, d_{F} \equiv \kappa_{F} / \kappa_{0}$, and $d_{a} \equiv\left(\lambda \Phi \gamma / \kappa_{0}\right)$. The stationary solution takes the form

$$
\widehat{u}_{t}=b \widehat{u}_{t-1}-c \gamma \widehat{a}_{t}
$$

where $b \equiv \frac{1-\sqrt{1-4 d_{F} d_{L}}}{2 d_{F}}$ and $c \equiv \frac{\lambda \Phi / \kappa_{0}}{1-d_{F}\left(b+\rho_{a}\right)}$.

Equation (36) points to a number of properties of strict inflation targeting policies. First, the volatility of unemployment under that policy regime is proportional to $\gamma$, the degree of wage rigidities, since the coefficients $b$ and $c$ are independent of that parameter. Second, the unemployment rate displays some intrinsic persistence, i.e. some serial correlation beyond that inherited from productivity. The degree of intrinsic persistence is given by coefficient $b$, which was equal to $(1-\delta)(1-x)$ under the simplifying approximations made in the previous sections, and very close to it under plausible parameter calibrations, as shown below. Thus, the degree of intrinsic unemployment persistence depends critically on the separation rate $\delta$ and the steady state job finding rate $x$. In a "sclerotic" labor market, that is, a market with low $x$ and low $\delta$, and under strict inflation targeting, unemployment will display strong persistence, well beyond that inherited from productivity. Persistence will be much lower in a fluid labor market, a market with high $x$ and high $\delta .^{10}$

Finally, note that the previous equation also characterizes the evolution of unemployment under flexible prices, since the allocation consistent with price stability replicates the one associated with the flexible price equilibrium.

10. The hypothesis that more sclerotic markets might lead to more persistence to unemployment was explored empirically by Barro (1988). 


\subsection{Optimal Monetary Policy}

We are now ready to characterize optimal policy. To simplify the analysis and avoid well understood but peripheral issues, we assume that unemployment fluctuates around a steady state value which corresponds to that of the constrained efficient allocation. As shown in Appendix A, a second order approximation to the welfare losses of the representative household around that steady state is proportional to:

$$
E_{0} \sum_{t=0}^{\infty} \beta^{t}\left(\pi_{t}^{2}+\alpha_{u} \widehat{u}_{t}^{2}\right)
$$

where $\alpha_{u} \equiv \lambda(1+\phi) \chi(1-u)^{\phi-1} / \epsilon>0$.

Hence the monetary authority will seek to minimize (37) subject to the sequence of equilibrium constraints given by $(34)$, for $t=0,1,2, \ldots$ Clearly, given the form of the welfare loss function, the optimal policy will be somewhere between the two extreme policies discussed above. The first order conditions take the form:

$$
\begin{gathered}
2 \pi_{t}+\zeta_{t}-\zeta_{t-1}=0 \\
2 \alpha_{u} \widehat{u}_{t}+\kappa_{0} \zeta_{t}-\beta \kappa_{L} E_{t}\left\{\zeta_{t+1}\right\}-\beta^{-1} \kappa_{F} \zeta_{t-1}=0
\end{gathered}
$$

for $t=0,1,2, \ldots$ where $\zeta_{t}$ is the Lagrange multiplier associated with period $t$ constraint, and where $\zeta_{-1}=0$.

The dynamical system describing the optimal policy is thus composed of (38) and (39), together with inflation equation (34), and a process for productivity $a_{t}$. The solution to that dynamical system can be obtained using standard methods for linear stochastic difference equations (see, e.g., Blanchard and Kahn (1980)). The next section gives a sense of the quantitative properties of the model, based on a rough calibration, and with a focus on the implications of different labor markets - fluid versus sclerotic - for monetary policy. 


\section{$6 \quad$ Calibration and Quantitative Analysis}

We take each period to correspond to a quarter. For the parameters describing preferences we assume values commonly found in the literature: $\beta=0.99, \phi=1$, and $\epsilon=6$ (implying a gross steady state markup $\mathcal{M}=1.2$ ).

We set $\lambda=1 / 12$, which is consistent with an average duration of prices between three and four quarters, in accordance with much of the micro and macro evidence on price setting. Having no hard evidence on the degree of real wage rigidities, we set $\gamma$ equal to 0.5 , the midpoint of the admissible range. ${ }^{11}$

In order to calibrate $\alpha$ we exploit a simple mapping between our model and the standard DMP model. In the latter, the expected cost per hire is proportional to the expected duration of a vacancy, which in the steady state is given by $V / H$ where $V$ denotes the number of vacancies. Assuming a matching function of the form $H=Z U^{\eta} V^{1-\eta}$, we have $V / H=Z^{\frac{1}{\eta-1}}(H / U)^{\frac{\eta}{1-\eta}}$. Hence, the parameter $\alpha$ in our hiring cost function corresponds to $\eta /(1-\eta)$ in the DMP model. Since estimates of $\eta$ are typically close to $1 / 2$, we assume $\alpha=1$ in our baseline calibration.

We then choose the remaining coefficients to capture two different types of labor markets, through two different calibrations. Our baseline calibration attempts to capture the fluid U.S. labor market. We choose parameters so the unemployment rate is equal to $5 \%$, and the job finding rate $x$ is equal to 0.7 (this quarterly job finding rate corresponds, approximately, to a monthly rate of 0.3 , consistent with U.S. evidence). ${ }^{12}$ The alternative calibration attempts to capture the more sclerotic continental European labor market. We choose parameters so the unemployment rate is $10 \%$, and $x=0.25$ (consistent with a monthly job finding rate of 0.1$)$.

These choices of $x$ and $u$ determine in turn the separation rate, through the

11. Under an overly strict interpretation of our model, $\gamma$ can be obtained through a regression of real wage growth on productivity growth — which is exogenous in our model. Such a regression yields a coefficient between 0.3 and 0.4 using postwar U.S. data, so a value for $\gamma$ between 0.6 and 0.7. Stepping outside our model, obvious caveats apply, from the measurement of productivity growth, to the direction of causality.

12. We compute the equivalent quarterly rate as $x_{m}+\left(1-x_{m}\right) x_{m}+\left(1-x_{m}\right)^{2} x_{m}$, where $x_{m}$ is the monthly job finding rate. 
relation $\delta=u x /((1-u)(1-x))$. This yields a value for $\delta$ of 0.12 for the United States, and 0.04 for continental Europe.

The next step is to choose a value for $B$, which determines the level of hiring costs. Notice that, in the steady state, hiring costs represent a fraction $\delta g=\delta B x^{\alpha}$ of GDP. Lacking any direct evidence, we choose $B$ so that under our baseline calibration for the United States, that fraction equals one percent of GDP, which seems a plausible upper bound. This implies $B=0.01 /(0.12)(0.7) \simeq 0.12$. We use this value of $B$ for both calibrations.

Finally, we use equation (9), which gives the constrained-efficient value of $x$ to tie down the value of $\chi$. This implies $\chi \simeq 1.03$ for the United States, and $\chi \simeq 1.22$ for Europe. ${ }^{13}$ The implied value of $\alpha_{u}$ is 0.0237 for the U.S. calibration and 0.0283 for Europe. ${ }^{14}$

\subsection{The Dynamic Effects of Productivity Shocks}

Figures 1 and 2 summarize the effects of a productivity shock under alternative monetary policies, for each of the two calibrations of the labor market. In Figure 1 we assume a purely transitory shock $\left(\rho_{a}=0\right)$, which allows us to isolate the model's intrinsic persistence, whereas in Figure 2 we assume $\rho_{a}=0.9$, a more realistic degree of persistence. In each figure we display the responses of inflation and unemployment for both the U.S. and European labor market calibrations. In all cases we report responses to a one-percent decline in productivity. All the responses are shown in percentage points, and in annual terms in the case of inflation.

We begin by discussing the case of a transitory shock.

13. Note that our model can only account for a higher efficient steady state unemployment rate in Europe by assuming a larger disutility of labor. Alternatively, we could have assumed an efficient steady state only for the United States, and impose the implied $\chi$ to the European calibration as well. In that case, however, the steady state unemployment for Europe would not be efficient and an additional linear term would appear in the loss function, complicating the analysis in an uninteresting (and well understood) way.

14. Such a (seemingly low) value is of the same order of magnitude as the weight on the output gap in calibrated loss functions found in the literature. 
The top left panel of Figure 1 shows the response of inflation to the adverse transitory productivity shock, under a policy that fully stabilizes unemployment. The response is nearly identical for both calibrations, implying a one-period rise in inflation of less than 20 basis points, with a subsequent return to its initial level once the shock dies out. The top right panel shows the response of unemployment to an identical adverse productivity shock, under a policy that fully stabilizes inflation. Unemployment rises by about 65 basis points on impact in the U.S. calibration, 50 basis points in the European one. Unemployment remains above its initial value well after the shock has vanished, with the persistence being significantly greater under the European calibration.

The bottom left and right panels of Figure 1 show, respectively, the response of inflation and unemployment under the optimal monetary policy. The optimal policy strikes a balance between the two extreme policies, and achieves a more muted response of both inflation and unemployment (note that, to facilitate comparison, the scale of the graph is the same across policy regimes, for any given variable). The differences in the responses across the two calibrations are small. Interestingly, the persistence in both variables is tiny (though not zero) under both calibrations. Perhaps the most salient feature of the exercise is the substantial reduction in unemployment volatility under the optimal policy relative to a constant inflation policy, achieved at a relatively small cost in terms of inflation volatility.

Figure 2 displays corresponding results, but under the assumption that $\rho_{a}=0.9$, a more realistic degree of persistence.

The response of inflation under the constant unemployment policy, shown in the top left panel of Figure 2, is now much larger, with an increase of about 150 basis points on impact under both calibrations. This amplification effect reflects the forward looking nature of inflation and the persistent anticipated effects on real marginal costs generated by the interaction of the shock and real wage rigidities. Note also that inflation inherits the persistence of the shock, as implied by (35). The response of unemployment under a strict inflation targeting policy, shown on the top right panel, is also much larger with a persistent shock. The un- 
employment rate increases on impact by about 3 percentage points under both calibrations, a sizeable rise. In both cases, unemployment is highly persistent, and displays a prominent hump-shaped pattern, reaching a maximum rise of about 8 percentage points (!) in the case of Europe. ${ }^{15}$ The degree of persistence is remarkably larger under the European calibration, for the reasons discussed earlier.

The bottom panels show the behavior of inflation and unemployment under the optimal monetary policy. The increase in unemployment is 50 basis points under the U.S. calibration, about half that size under the European one. Note that the size of such responses is several times smaller than under the strict inflation targeting policy. The price for having a smoother unemployment path is persistently higher inflation, with the latter variable increasing on impact by about 1 and 1.4 percentage points in the U.S. and Europe. We note that the optimal policy is "tougher on inflation" (i.e. more hawkish) in the U.S. relative to Europe. This is due to the larger cost, in the form of a persistent rise in unemployment, that results under the European calibration from policies that seek to stabilize inflation in response to an adverse productivity shocks, as illustrated by the extreme policy analyzed above.

Table 1 summarizes the main properties of the policies analyzed above under the two calibrations. More specifically, for each policy and calibration, the first two columns show the implied standard deviation of inflation and unemployment, with the standard deviation of productivity being normalized to unity (and given $\rho_{a}=0.9$ ). In addition, we report the welfare loss implied by each policy relative to that implied by the optimal policy. One finding seems worth noting: The welfare losses associated with a strict inflation targeting policy appear to be very large relative to the optimal policy, especially so under the European calibration, which yields losses that are 25 times larger than under the optimal policy. This is again a consequence of the substantial volatility of unemployment required to keep inflation unchanged in the face of productivity shocks.

In addition to the two extreme policies and the optimal policy, Table 1 displays

15. While the size of this response may be viewed as unrealistically large, it is important to keep in mind that the policy assumed is also unrealistically extreme. 
the statistics corresponding to an "optimized simple rule." The latter is an interest rate rule of the form

$$
i_{t}=\rho+\phi_{\pi} \pi_{t}+\phi_{u} \widehat{u}_{t}
$$

where coefficients $\phi_{\pi}$ and $\phi_{u}$ are chosen, for each calibration, in order to minimize the welfare losses. The optimization is done numerically, searching over a grid spanning the intervals $\phi_{\pi} \in(1,5]$ and $\phi_{u} \in[-5,0] .{ }^{16}$ The optimal coefficients are $\phi_{\pi}=5$ and $\phi_{u}=-0.8$ for the U.S. calibration, and $\phi_{\pi}=2$ and $\phi_{u}=-0.6$ for the European calibration. The optimized simple rule puts a smaller weight on inflation stabilization under the European calibration, in a way consistent with our findings based on the optimal rule. In any event, as the results shown in the table make clear, following such a simple rule reduces considerably the losses relative to the extreme policies under both calibrations and, at least under the European one, comes close to replicating the welfare outcome obtained under the optimal policy.

\section{$7 \quad$ Relation to the Literature}

Our model combines four main elements: (1) standard preferences (concave utility of consumption and leisure), (2) labor market frictions, (3) real wage rigidities, (4) price staggering. As a result, it is related to a large and rapidly growing literature.

Merz (1995) and Andolfatto (1996) were the first to integrate (1) and (2), by introducing labor market frictions in an otherwise standard RBC model. In particular, Merz derived the conditions under which Nash bargaining would or would not deliver the constrained-efficient allocation. Both models are richer than ours in allowing for capital accumulation, and in the case of Andolfatto, for having both an extensive margin (through hiring) and an intensive margin (through adjustment of hours) for labor. In both cases, the focus was on the dynamic ef-

16. In the case of the U.S. calibration, allowing for a larger range of values yields very large (in absolute values) coefficients for inflation and unemployment, with negligible gains in terms of welfare. 
fects of productivity shocks, and in both cases, the model was solved through simulations.

Chéron and Langot (2000), Walsh (2003) and Trigari (2006), have integrated (1), (2) and (4), by allowing for Calvo nominal price setting by firms. Their models are again much richer than ours. Walsh allows for endogenous separations. Chéron and Langot, as well as Trigari, allow for both an extensive and an intensive margin for labor, with efficient Nash bargaining over hours and the wage. In addition Trigari considers "right to manage" bargaining, with the firm choosing freely hours ex-post. Those models are too large to be analytically tractable, and are solved through simulations. The focus of Walsh and Trigari's papers is on the dynamic effects of nominal shocks, while Chéron and Langot study the ability of the model with both productivity and monetary shocks to generate a Beveridge curve as well as a Phillips curve. More recent papers, by Walsh (2005), Trigari (2005), Moyen and Sahuc (2005), and Andrés et al. (2006) among others, introduce a number of extensions, from habit persistence in preferences, to capital accumulation, to the implications of Taylor rules. The models in these papers are relatively complex DSGE models, which need to be studied through calibration and simulations.

Shimer (2005) and Hall (2005) were the first to integrate (2) and (3). Shimer argued that, in the standard DMP model with Nash bargaining, wages were too flexible, and the response of unemployment to productivity shocks was too small. Hall (2005) showed first the scope for and then the implications of real wage rigidities in that class of models. These models differ from ours because of their assumption of linear preferences (in addition to their being purely real models). We have shown earlier the implications of this difference. But our results, using a standard utility specification, reinforce their conclusion that real wage rigidities are probably needed to explain fluctuations.

Gertler and Trigari (2005) have explored the implications of integrating (1), (2) and (3). Their model allows for standard preferences, labor market frictions, and real wage staggering a la Calvo. Being a real model, however, it has no room for nominal rigidities. Their model is again too complex to be solved analytically, and is studied through simulations. Their focus is on the dynamic effects 
of productivity shocks.

Two papers have explored a structure closely related to ours, but with staggered nominal wage setting rather than real wage rigidity. Thomas (2007) focuses on the role of monetary policy in that context, with implications substantially different from ours - which suggests that a more thorough exploration of the different implications of the two alternative assumptions is needed. Gertler, Sala, and Trigari (2007) estimate a model with standard preferences, labor market frictions, and both nominal wage and price rigidities.

The three papers closest to ours are by Krause and Lubik (2007), Christoffel and Linzert (2005) and Faia (2006). They integrate (1) to (4), with standard preferences, labor market frictions, real wage rigidities, and nominal price staggering by firms. The three models are substantially richer than ours, and are solved through simulations. The main focus of Krause and Lubik is on the relation between inflation, marginal cost, and real wages, in the presence of matching frictions and endogenous separations. The main focus of Christoffel and Linzert is on inflation persistence in response to monetary policy shocks. The main focus of Faia is on the performance of simple monetary rules. Again, we see the comparative advantage of our paper as being in its simplicity, its analytical characterization of the effects of productivity shocks and optimal monetary policy in relation to labor market characteristics. We think that our analytical model is a needed step in the development and full understanding of these richer but more complex models.

\section{Conclusions}

We have constructed a model with labor market frictions, real wage rigidities, and staggered price setting. We believe that the three ingredients above are all needed if one is to explain movements in unemployment, the effects of productivity shocks on the economy, and the role of monetary policy in shaping those effects.

From a positive point of view, we have shown that, in such an economy, a central variable is the degree of labor market tightness. A tighter labor market increases marginal cost, which in turn affects inflation. The relation between inflation and 
unemployment then depends on the relation between labor market tightness and unemployment, and this relation varies depending on labor market characteristics. In fluid labor markets such as the United States, labor market tightness varies more closely with unemployment; in sclerotic labor markets, such as those in continental Europe, labor market tightness varies more closely with the change in unemployment. These differences lead in turn to important differences in the response of the economy to shocks. Under inflation stabilization for example, the same productivity shock has more persistent effects in a sclerotic than in a fluid labor market.

From a normative point of view, we have shown that, in the presence of labor market frictions and real wage rigidities, strict inflation stabilization does not deliver the best monetary policy. As in Blanchard and Gali (2007), the reason is that distortions vary with shocks. As a result, strict inflation stabilization can lead to inefficient, large, and persistent, movements in unemployment in response to productivity shocks. These effects can be particularly large and persistent in sclerotic labor markets. Optimal monetary policy implies some accommodation of inflation, and limits the size of the fluctuations in unemployment. 


\section{Appendix A: Derivation of the Welfare Loss Function}

Under our assumed utility specification we have:

$$
u\left(C_{t}\right)=\log C_{t}=c+\widehat{c}_{t}
$$

and

$$
\begin{aligned}
v\left(N_{t}\right) & =\chi \frac{N_{t}^{1+\phi}}{1+\phi} \\
& \simeq \chi \frac{N^{1+\phi}}{1+\phi}+\chi N^{1+\phi}\left(\frac{N_{t}-N}{N}\right)+\frac{1}{2} \phi \chi N^{1+\phi}\left(\frac{N_{t}-N}{N}\right)^{2} \\
& \simeq \chi \frac{N^{1+\phi}}{1+\phi}+\chi N^{1+\phi} \widehat{n}_{t}+\frac{1}{2}(1+\phi) \chi N^{1+\phi} \widehat{n}_{t}^{2}
\end{aligned}
$$

where we have made use of the fact that up to second order $\frac{N_{t}-N}{N} \simeq \widehat{n}_{t}+\frac{1}{2} \widehat{n}_{t}^{2}$. Hence, the deviation of period utility from its steady state value, denoted by $U_{t}$, is given by

$$
U_{t} \simeq \widehat{c}_{t}-\chi N^{1+\phi} \widehat{n}_{t}-\frac{1}{2}(1+\phi) \chi N^{1+\phi} \widehat{n}_{t}^{2}
$$

Next we derive an equation that relates, up to a second order approximation, $\widehat{c}_{t}$ and $\widehat{n}_{t}$. Market clearing for good $i$ requires that $A_{t}\left(N_{t}(i)-g\left(x_{t}\right) H_{t}(i)\right)=C_{t}(i)$. Integrating over $i$ yields:

$$
\begin{aligned}
A_{t}\left(N_{t}-g\left(x_{t}\right) H_{t}\right) & =\int_{0}^{1} C_{t}(i) d i \\
& =C_{t} \int_{0}^{1} \frac{C_{t}(i)}{C_{t}} d i \\
& =C_{t} \int_{0}^{1}\left(\frac{P_{t}(i)}{P_{t}}\right)^{-\epsilon} d i \\
& \equiv C_{t} D_{t}
\end{aligned}
$$

where $D_{t} \equiv \int_{0}^{1}\left(\frac{P_{t}(i)}{P_{t}}\right)^{-\epsilon} d i$.

Thus we can write

$$
\frac{C_{t} D_{t}}{A_{t}}=N_{t}-g\left(x_{t}\right) H_{t}
$$


Under the assumption that $g$ is small enough, so that the terms involving $g \widehat{n}_{t}$ are of second order, we have

$$
\begin{aligned}
N_{t}-g\left(x_{t}\right) H_{t} \simeq & (1-\delta g) N+N\left(\frac{N_{t}-N}{N}\right)-\alpha g N \delta \widehat{x}_{t}-g N\left(\widehat{n}_{t}-(1-\delta) \widehat{n}_{t-1}\right) \\
\simeq & (1-\delta g) N+N\left(\widehat{n}_{t}+\frac{1}{2} \widehat{n}_{t}^{2}\right)-\alpha g N\left(\widehat{n}_{t}-(1-\delta)(1-x) \widehat{n}_{t-1}\right) \\
& -g N\left(\widehat{n}_{t}-(1-\delta) \widehat{n}_{t-1}\right) \\
\simeq & (1-\delta g) N+\frac{1}{2} N \widehat{n}_{t}^{2}+N(1-g(1+\alpha)) \widehat{n}_{t} \\
& +g N(1-\delta)(1+\alpha(1-x)) \widehat{n}_{t-1}
\end{aligned}
$$

where we have made use of equation (26) as well as the fact that $g^{\prime} x=\alpha g$. Thus,

$\frac{C_{t} D_{t}}{A_{t}(1-\delta g) N}=1+\frac{1}{2} \frac{1}{1-\delta g} \widehat{n}_{t}^{2}+\frac{1-g(1+\alpha)}{1-\delta g} \widehat{n}_{t}+\frac{g(1-\delta)(1+\alpha(1-x))}{1-\delta g} \widehat{n}_{t-1}$

Taking logs, and approximating the resulting right hand term up to second order using the fact that $\log \left(1+\widehat{z}_{t}\right) \simeq \widehat{z}_{t}-\frac{1}{2} \widehat{z}_{t}^{2}$, we have

$$
\widehat{c}_{t}=\widehat{a}_{t}-d_{t}+\xi_{0} \widehat{n}_{t}+\xi_{1} \widehat{n}_{t-1}
$$

where $\xi_{0} \equiv \frac{1-g(1+\alpha)}{1-\delta g}$ and $\xi_{1} \equiv \frac{g(1-\delta)(1+\alpha(1-x))}{1-\delta g}$.

Lemma: up to a second order approximation, $d_{t} \equiv \log D_{t} \simeq \frac{\epsilon}{2} \operatorname{var}_{i}\left(p_{t}(i)\right)$.

Proof: See appendix B.

Using (40) and (41), we can write the expected discounted sum of period utilities as follows: 


$$
\begin{aligned}
E_{0} \sum_{t=0}^{\infty} \beta^{t} U_{t} \simeq & -\frac{\epsilon}{2} E_{0} \sum_{t=0}^{\infty} \beta^{t} \operatorname{var}_{i}\left(p_{t}(i)\right)-\frac{1}{2}(1+\phi) \chi N^{1+\phi} E_{0} \sum_{t=0}^{\infty} \beta^{t} \widehat{n}_{t}^{2} \\
& +E_{0} \sum_{t=0}^{\infty} \beta^{t}\left(\xi_{0}+\beta \xi_{1}-\chi N^{1+\phi}\right) \widehat{n}_{t}+\text { t.i.p. }
\end{aligned}
$$

where t.i.p. denotes terms independent of policy.

Assuming that the economy fluctuates around the efficient steady state, we can use (9) to show that the coefficient on $\widehat{n}_{t}$ equals zero.

The following result allows us to express the cross-sectional variance of prices as a function of inflation:

Lemma: $\sum_{t=0}^{\infty} \beta^{t} \operatorname{var}_{i}\left(p_{t}(i)\right)=\frac{1}{\lambda} \sum_{t=0}^{\infty} \beta^{t} \pi_{t}^{2}$

Proof: Woodford (2003).

Combining the previous results, together with our definition of the unemployment rate $u_{t}$, we can write the welfare losses from fluctuations around the efficient steady state (ignoring terms independent of policy) as

$$
\begin{aligned}
\mathbb{L} & \equiv \frac{1}{2} E_{0} \sum_{t=0}^{\infty} \beta^{t}\left[\frac{\epsilon}{\lambda} \pi_{t}^{2}+(1+\phi) \chi(1-u)^{\phi-1} \widehat{u}_{t}^{2}\right] \\
& =\frac{1}{2} \frac{\epsilon}{\lambda} E_{0} \sum_{t=0}^{\infty} \beta^{t}\left(\pi_{t}^{2}+\alpha_{u} \widehat{u}_{t}^{2}\right)
\end{aligned}
$$

where $\alpha_{u} \equiv \frac{\lambda(1+\phi) \chi(1-u)^{\phi-1}}{\epsilon}>0$.

\section{Appendix B}

From the definition of the price index, in a neighborhood of the zero inflation steady state: 


$$
\begin{aligned}
1 & =\int_{0}^{1}\left(\frac{P_{t}(i)}{P_{t}}\right)^{1-\epsilon} d i \\
& =\int_{0}^{1} \exp \left\{(1-\epsilon)\left(p_{t}(i)-p_{t}\right)\right\} d i \\
& \simeq 1+(1-\epsilon) \int_{0}^{1}\left(p_{t}(i)-p_{t}\right) d i+\frac{(1-\epsilon)^{2}}{2} \int_{0}^{1}\left(p_{t}(i)-p_{t}\right)^{2} d i
\end{aligned}
$$

thus implying

$$
p_{t} \simeq \int_{0}^{1} p_{t}(i) d i+\frac{(1-\epsilon)}{2} \int_{0}^{1}\left(p_{t}(i)-p_{t}\right)^{2} d i
$$

By definition,

$$
\begin{aligned}
D_{t} & \equiv \int_{0}^{1}\left(\frac{P_{t}(i)}{P_{t}}\right)^{-\epsilon} d i \\
& =\int_{0}^{1} \exp \left\{-\epsilon\left(p_{t}(i)-p_{t}\right)\right\} d i \\
& \simeq 1-\epsilon \int_{0}^{1}\left(p_{t}(i)-p_{t}\right) d i+\frac{\epsilon^{2}}{2} \int_{0}^{1}\left(p_{t}(i)-p_{t}\right)^{2} d i \\
& \simeq 1+\frac{\epsilon(1-\epsilon)}{2} \int_{0}^{1}\left(p_{t}(i)-p_{t}\right)^{2} d i+\frac{\epsilon^{2}}{2} \int_{0}^{1}\left(p_{t}(i)-p_{t}\right)^{2} d i \\
& =1+\frac{\epsilon}{2} \int_{0}^{1}\left(p_{t}(i)-p_{t}\right)^{2} d i
\end{aligned}
$$

It follows that $d_{t} \simeq(\epsilon / 2) \operatorname{var}_{i}\left(p_{t}(i)\right)$ up to a second order approximation. 


\section{References}

Andolfatto, David (1996): "Business Cycles and Labor Market Search," American Economic Review, 86-1, 112-132

Andrés, Javier, Rafael Domenech, and Javier Ferri (2006): "Price Rigidity and the Volatility of Vacancies and Unemployment," mimeo, Universidad de Valencia.

Barro, Robert (1988): "The Persistence of Unemployment," American Economic Review, vol. 78-2, May, 32-37.

Blanchard, Olivier J., and Jordi Galí (2007): "Real Wage Rigidities and the New Keynesian Model," Journal of Money Credit and Banking, February, 35-66

Chéron, Arnaud, and François Langot (2000): "The Phillips and Beveridge Curves Revisited," Economics Letters 69, 371-376.

Christoffel, Kai, and Tobias Linzert (2005): "The Role of Real Wage Rigidities and Labor Market Frictions for Unemployment and Inflation Dynamics", Discussion Paper 556, European Central Bank

Erceg, Christopher J., Dale W. Henderson, and Andrew T. Levin (2000): "Optimal Monetary Policy with Staggered Wage and Price Contracts," Journal of Monetary Economics vol. 46, no. 2, 281-314.

Faia, Ester (2006): "Optimal Monetary Policy with Labor Market Frictions," Working Paper 698, November, European Central Bank

Galí, Jordi and Mark Gertler (1999): "Inflation Dynamics: A Structural Econometric Analysis," Journal of Monetary Economics, vol. 44, n2, 195-222, 1999

Gertler, Mark, and Antonella Trigari (2005): "Unemployment Fluctuations with Staggered Nash Wage Bargaining," mimeo, November.

Gertler, Mark, Luca Sala, and Antonella Trigari (2007): "An Estimated Monetary DSGE Model with Unemployment and Staggered Nominal Wage Bargaining," mimeo October.

Hagedorn, Marcus, and Iourii Manovskii (2006): "The Cyclical Behavior of Equilibrium Unemployment and Vacancies Revisited," mimeo University of Chicago, April 
Hall, Robert (2005): "Employment Fluctuations with Equilibrium Wage Stickiness," American Economic Review vol. 95, no. 1, 50-64.

Krause, Michael, Thomas Lubik (2007): "The (Ir)relevance of Real Wage rigidities in the New Keynesian Model with Search Frictions," Journal of Monetary Economics, 54, April, 706-727.

Merz, Monica (1995): "Search in the Labor Market and the Real Business Cycle", Journal of Monetary Economics, 36, 269-300

Moyen, Stephane, and Jean Guillaume Sahuc (2005): "Incorporating labour market frictions into an optimizing-based monetary policy model", Economic Modelling 22, 159-186

Pissarides, Christopher (2000): Equilibrium Unemployment Theory, MIT Press.

Rotemberg, Julio and Michael Woodford (1999): "The Cyclical Behavor of Prices and Costs," in Handbook of Macroeconomics, J. Taylor and M. Woodford eds., Elsevier-North Holland.

Shimer, Robert (2005): "The Cyclical Behavior of Equilibrium unemployment and Vacancies," American Economic Review vol. 95, no. 1, 25-49.

Thomas, Carlos (2006): "Search and Matching Frictions and Optimal Monetary Policy," job market paper, LSE, October

Trigari, Antonella (2005): "Equilibrium Unemployment, Job flows, and Inflation Dynamics," ECB WP\#304.

Trigari, Antonella (2006): "The Role of Search Frictions and Bargaining of Inflation Dynamics", mimeo.

Walsh, Carl (2003): "Labor Market Search and Monetary Shocks", in Elements of Dynamic Macroeconomic Analysis, S. Altug, J. Chadha and C. Nolan eds.

Walsh, Carl (2005): "Labor market search, Sticky Prices, and Interest Rate Rules", Review of Economic Dynamics, 8, 829-849 
Figure 1: Dynamic Responses to a Transitory Productivity Shock
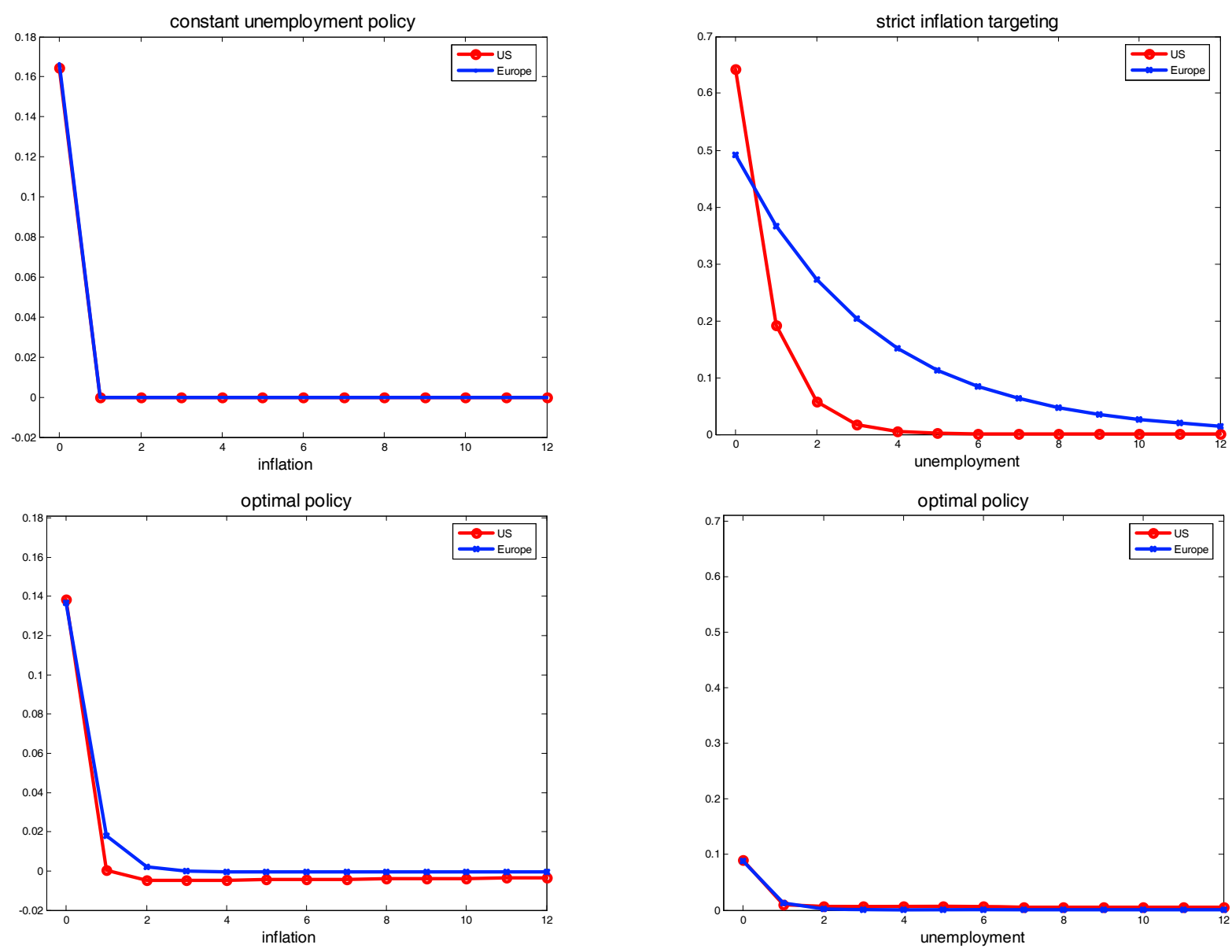
Figure 2: Dynamic Responses to a Persistent Productivity Shock
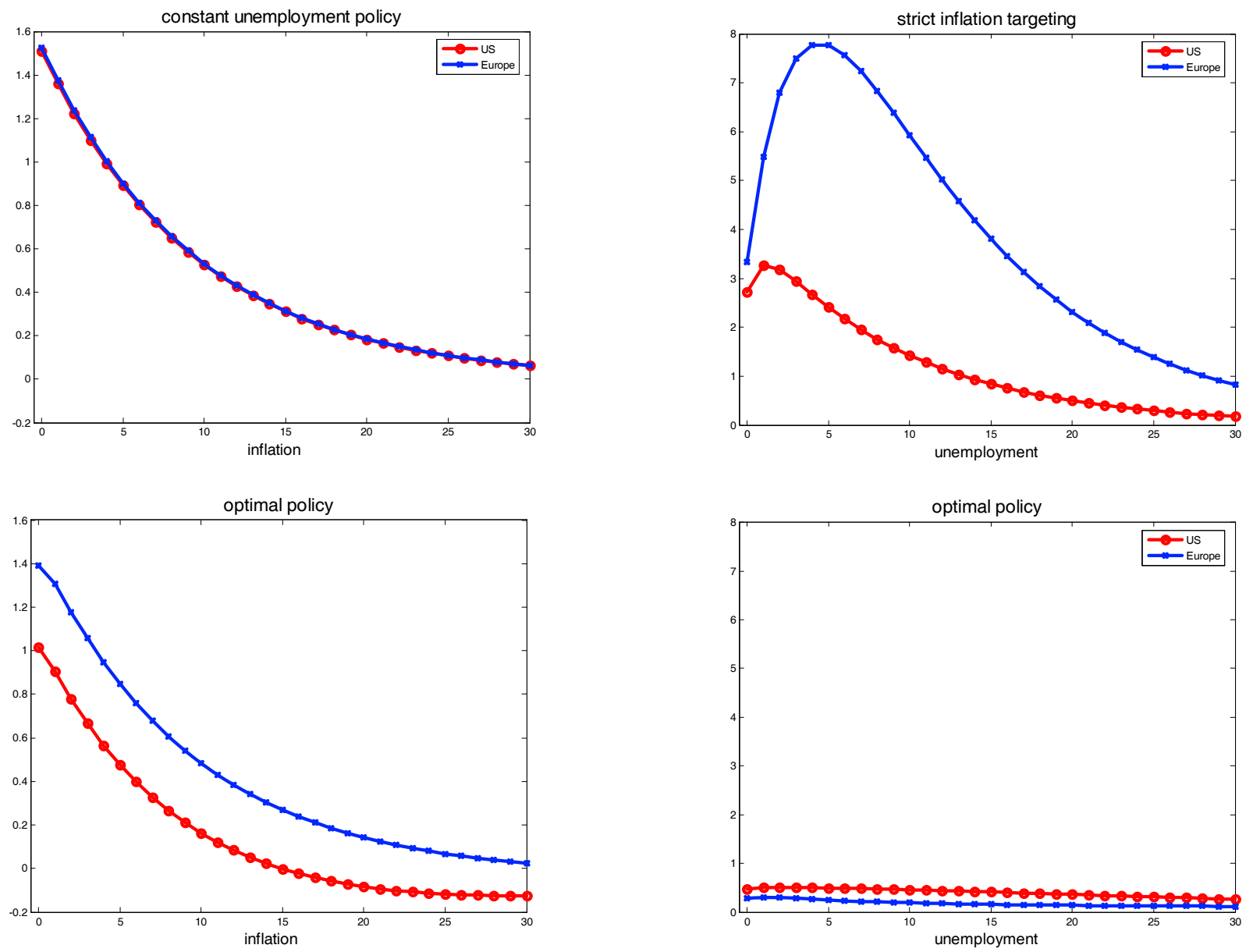
Table 1: Properties of Alternative Policy rules

\begin{tabular}{|l|ccc|ccc|}
\hline & \multicolumn{3}{|c|}{ U.S. } & \multicolumn{3}{c|}{ Europe } \\
\hline & $\sigma(\pi)$ & $\sigma(u)$ & Loss & $\sigma(\pi)$ & $\sigma(u)$ & Loss \\
\hline Optimal & 0.88 & 1.08 & 1.0 & 1.43 & 0.77 & 1.0 \\
\hline Constant $u$ & 1.48 & 0 & 1.87 & 1.52 & 0 & 1.08 \\
\hline Constant $\pi$ & 0 & 3.76 & 4.39 & 0 & 11.27 & 25.6 \\
\hline Optimized Simple Rule & 1.07 & 1.11 & 1.34 & 1.47 & 0.42 & 1.04 \\
\hline & & & & &
\end{tabular}

